\title{
Low pre-transplant levels of mannose- binding lectin are associated with viral infections and mortality after haematopoietic allogeneic stem cell transplantation
}

M. Puente ${ }^{1,2}$, C. Fariñas-Alvarez ${ }^{3 \dagger}$, A. Moreto ${ }^{1,2}$, P. Sánchez-Velasco ${ }^{3}$, J. G. Ocejo-Vinyals ${ }^{3 \dagger}$, M. C. Fariñas ${ }^{4^{*}+}$ (i) and on behalf of SCT team

\begin{abstract}
Background: Mannose-binding lectin (MBL) is a key component of innate immunity. Low serum MBL levels, related to promoter polymorphism and structural variants, have been associated with an increased risk of infection. The aim of this work was to analyse the incidence and severity of infections and mortality in relation to the MBL2 genotype and MBL levels in patients underwent allogeneic haematopoietic stem cell transplantation (Allo-HSCT).

Results: This was a prospective cohort study of 72 consecutive patients underwent Allo-HSCT between January 2007 and June 2009 in a tertiary referral centre. Three periods were considered in the patients' follow-up: the early period ( $0-30$ days after Allo-HSCT), the intermediate period (30-100 days after Allo-HSCT) and the late period (> 100 days after Allo-HSCT). A commercial line probe assay for MBL2 genotyping and an ELISA Kit were used to measure MBL levels. A total of 220 episodes of infection were collected in the 72 patients. No association between donor or recipient MBL2 genotype and infection was found. The first episode of infection presented earlier in patients with pre-transplant MBL levels of $<1000 \mathrm{ng} / \mathrm{ml}$ (median $6 \mathrm{~d}$ vs $8 \mathrm{~d}, p=0.036$ ). MBL levels $<1000 \mathrm{ng} / \mathrm{ml}$ in the pre-transplant period (risk ratio (RR) 2.48, 95\% Cl 1.00-6.13), neutropenic period (0-30 days, RR 3.28, 95\% Cl 1.53-7.06) and intermediate period (30-100 days, RR $2.37,95 \% \mathrm{Cl} 1.15-4.90$ ) were associated with increased risk of virus infection. No association with bacterial or fungal disease was found. Mortality was associated with pre-transplant MBL levels $<1000 \mathrm{ng} / \mathrm{ml}$ (hazard ratio 5.55, 95\% Cl 1.17-26.30, $p=0.03$ ) but not with MBL2 genotype.

Conclusions: Patients who underwent Allo-HSCT with low pre-transplant MBL levels presented the first episode of infection earlier and had an increased risk of viral infections and mortality in the first 6 months post-transplant. Thus, pre-transplant MBL levels would be important in predicting susceptibility to viral infections and mortality and might be considered a biomarker to be included in the pre-transplantation risk assessment.
\end{abstract}

Keywords: Allo-HSCT, Genetic polymorphism, MBL, Infection, Outcome

\footnotetext{
* Correspondence: farinasc@unican.es; mcarmen.farinas@scsalud.es

${ }^{+}$C Fariñas-Álvarez, JG Ocejo-Vinyals and MC Fariñas share senior authorship in this study.

${ }^{4}$ Infectious Diseases Unit, Hospital Universitario Marqués de Valdecilla, IDIVAL,

University of Cantabria, Av. Valdecilla s/n, 39008 Santander, Spain

Full list of author information is available at the end of the article
}

(c) The Author(s). 2019 Open Access This article is distributed under the terms of the Creative Commons Attribution 4.0 International License (http://creativecommons.org/licenses/by/4.0/), which permits unrestricted use, distribution, and

reproduction in any medium, provided you give appropriate credit to the original author(s) and the source, provide a link to the Creative Commons license, and indicate if changes were made. The Creative Commons Public Domain Dedication waiver (http://creativecommons.org/publicdomain/zero/1.0/) applies to the data made available in this article, unless otherwise stated. 


\section{Background}

Despite the improvement in diagnosis and therapy, invasive bacterial, virus and fungal infections are still some of the most important barriers to the success of allogeneic haematopoietic stem cell transplantation (Allo-HSCT) [13]. Mannose-binding lectin (MBL), a key component of innate immunity response, is a $\mathrm{C}$-type serum lectin that binds microbial surface carbohydrates and mediates opsono-phagocytosis both directly and by activation of the lectin complement pathway $[4,5]$. Mutations in the structural and regulatory sequence of the $M B L 2$ gene lead to inter-individual variations in serum MBL levels which have been associated with increased risk of infections [57]. Low serum MBL levels, related to promoter polymorphism and structural variants, have been associated with an increased risk of infection [7].

In patients with haematological malignancies receiving chemotherapy, increased susceptibility to infection and prolonged duration of febrile neutropenic episodes have been associated with MBL deficiency [8-10]. However, these observations were not consistent in all study cohorts [11-13]. In autologous HSCT [14-17] showed conflicting results regarding the influence of $M B L 2$ genotype and functional MBL deficiency on infection risk. In myeloablative, total body irradiation (TBI) -conditioned transplantation-, $M B L 2$ variants have been associated with an increased risk of infection [18]. Nonetheless, other studies involving Allo-HSCT showed contradictory results regarding the influence of $M B L 2$ polymorphisms and MBL deficiency on infection risk [18-25]. In addition, it is difficult to compare these different studies, because of some studies focused on MBL levels while others determined $M B L 2$ genotype, and even more because of different MBL cut-off levels and different $M B L 2$ genotype or haplotype combinations that are considered deficient [14-25]. Furthermore, over the years, research on MBL in Allo-HSCT has addressed the question of whether or not MBL is associated with their prognosis without reaching clear conclusions [13].

The aim of our study was to investigate the incidence, severity of infections, and mortality according to $M B L 2$ genotype and MBL levels in a prospective cohort of myeloablative and non-myeloablative Allo-HSCT patients carrying out a follow up from the pre-transplant conditioning to 6 months after the transplantation.

\section{Results}

Infections

From February 28th, 2007 to June 30th, 2009, 77 consecutive Allo-HSCT patients were included in the study. Five patients were excluded for not following the sampling protocol. The main demographic data are shown in Table 1 and supplementary Table 1.
Table 1 Characteristics of 72 patients with Allo-HSCT

\begin{tabular}{|c|c|}
\hline \multicolumn{2}{|l|}{ Patients } \\
\hline Age (median years, range) & $44(13-63)$ \\
\hline Sex (male) & $35(48.6 \%)$ \\
\hline \multicolumn{2}{|l|}{ Haematologic disease } \\
\hline Acute Myeloblastic Leukaemia & $18(25.0 \%)$ \\
\hline Acute Lymphoblastic Leukaemia & $13(18.1 \%)$ \\
\hline Myelodysplastic syndrome & $8(11.1 \%)$ \\
\hline Myeloproliferative syndrome & $8(11.1 \%)$ \\
\hline Hodgkin Lymphoma & $6(8.3 \%)$ \\
\hline Multiple Myeloma & $5(6.9 \%)$ \\
\hline Chronic Lymphoproliferative Disorder & $7(9.7 \%)$ \\
\hline $\mathrm{NHL}^{\mathrm{a}}$ & $3(4.2 \%)$ \\
\hline Bone Marrow Aplasia & $3(4.2 \%)$ \\
\hline Waldeström Disease & $1(1.4 \%)$ \\
\hline \multicolumn{2}{|l|}{ Type of Transplant } \\
\hline Myeloablative & $38(52.8 \%)$ \\
\hline Non-myeloablative & $34(47.2 \%)$ \\
\hline \multicolumn{2}{|l|}{ Conditioning } \\
\hline Busulfan + Cyclophosphamide + /-ATG & $23(32.0 \%)$ \\
\hline Fludarabine + Melphalan + /-ATG & $18(25.0 \%)$ \\
\hline Radiotherapy + Cyclophosphamide + /-ATG & $12(16.7 \%)$ \\
\hline Busulfan + fludarabine & $11(15.3 \%)$ \\
\hline Others & $8(11.1 \%)$ \\
\hline \multicolumn{2}{|l|}{ MBL levels (ng/mL) (median, IQR ${ }^{b}$ ) } \\
\hline Pre-transplant & $1135(2918-466)$ \\
\hline Early period & 1997.5 (4056-464) \\
\hline Intermediate period & 1665 (3765-337.3) \\
\hline Late period & $1264(3219.5-468.4)$ \\
\hline
\end{tabular}

${ }^{\mathrm{a}} \mathrm{NHL}$ : Non-Hodgkin's Lymphoma

${ }^{b}$ IQR: interquartile range (75th-25th percentiles)

A total of 220 episodes of infection were collected, and 150 of them microbiologically documented (68.2\%). There were 4 (6.6\%) patients who had no infections during the follow up. Seventy-eight infections occurred in the early period, 52 in the intermediate period and 20 in the late period (Table 2). The average number of episodes per patient was $3(\mathrm{SD}=2.1)$, with a minimum of 1 and a maximum of 9 . The number of infections according to the conditioning regimen was $82.4 \%$ in myeloablative and $76.3 \%$ in non-myeloablative $(p=0.36)$. However, infections started later in patients with nonmyeloablative allo-HSCT (median of 6 days in myeloablative conditioning regimen versus 9 days non-myeloablative, $p=0.018)$, with a significant $\mathrm{HR}=1.76(95 \%$ CI $1.06-2.71)$.

Donors and recipients $M B L 2$ genotypes and infection $M B L 2$ genotypes were analysed in 61 (84.7\%) recipients and 38 (52.8\%) donors. Recipients and donors were 
Table 2 Microbiologically documented episodes of infection

\begin{tabular}{|c|c|c|c|c|}
\hline \multirow[t]{3}{*}{ Microorganisms } & \multicolumn{3}{|l|}{ Periods } & \multirow{3}{*}{$\begin{array}{l}\text { Total }{ }^{d} \\
N(\%)\end{array}$} \\
\hline & Neutropenic $^{a}$ & Intermediate ${ }^{b}$ & Late $^{c}$ & \\
\hline & N (\%) & N (\%) & N (\%) & \\
\hline Bacteria & $63(80.8)$ & $27(51.9)$ & $11(55.0)$ & $101(67.3)$ \\
\hline Gram-positive & $39(50.0)$ & $8(15.4)$ & $3(15.0)$ & $50(33.3)$ \\
\hline Gram-negative & $20(25.6)$ & $14(26.9)$ & $7(35.0)$ & $41(27.3)$ \\
\hline Polymicrobial & $4(5.1)$ & $5(9.6)$ & $1(5.0)$ & $10(6.7)$ \\
\hline Virus & $13(16.7)$ & $22(42.3)$ & $4(20.0)$ & $39(26.0)$ \\
\hline $\mathrm{CMV}^{\mathrm{e}}$ & $5(6.4)$ & 18 (34.6) & $4(20.0)$ & $27(18.0)$ \\
\hline Others non $\mathrm{CMV}^{f}$ & $8(10.3)$ & $4(7.7)$ & & $12(8.0)$ \\
\hline Fungi & $2(2.6)$ & $2(3.8)$ & $4(20.0)$ & $8(5.3)$ \\
\hline Candida & $2(2.6)$ & & $1(5.0)$ & $3(2.0)$ \\
\hline Aspergillus & & $2(3.8)$ & $3(15.0)$ & $5(3.3)$ \\
\hline P. jirovecii & & & $1(5.0)$ & $1(0.7)$ \\
\hline Protozoa & & $1(1.9)$ & & $1(0.7)$ \\
\hline Total & 78 & 52 & 20 & 150 \\
\hline
\end{tabular}

${ }^{a} 0-30$ days after Allo-HSCT; ${ }^{b} 30-100$ days after Allo-HSCT; ${ }^{c}>100$ days after Allo-HSCT

${ }^{\mathrm{d}}$ Total episodes of infection; ${ }^{\mathrm{e}} \mathrm{CMV}$ : Cytomegalovirus; ${ }^{\mathrm{f}}$ Others non CMV virus: neutropenic period ( 3 herpesvirus, 2 polyomavirus, 1 herpes simplex virus type 1,1 respiratory syncytial virus and 1 rotavirus), intermediate period ( 2 herpes simplex virus type 1, 1 adenovirus and 1 polyomavirus)

divided into two groups, each according to their $M B L 2$ genotype: 1) homozygous donors (AA) for wild type MBL2 genotype $(n=24)$ and $\mathrm{AO} / \mathrm{OO}$ donors $(n=14)$, which included heterozygous donors $(\mathrm{AO})(n=13)$ and homozygous mutant donors $(\mathrm{OO})(\mathrm{n}=1)$; and 2) recipients homozygous (AA) for wild type $M B L 2$ genotype $(n=34)$ and $\mathrm{AO} / \mathrm{OO}$ recipients $(n=27)$, which included heterozygous recipients $(\mathrm{AO})(n=23)$, and homozygous mutant recipients $(\mathrm{OO})(n=4)$ (supplementary Table 2$)$. We did not find a significant increase of microbiologically documented Gram-positive (RR 1.71; CI 95\% 0.903.28), Gram-negative (RR 1.56 CI 95\% 0.90-2.69), virus (RR 1.50 CI 95\% 0.69-3.24) or fungal infections (RR 1.00 CI 95\% 0.03-2.66) in patients whose donors had lowproducer $M B L 2$ genotypes (AO and $\mathrm{OO}$ genotypes). These findings did not differ when we tested different combinations of patient /donor MBL2 genotypes.

Recipients with low-producer $M B L 2$ genotypes (AO and $\mathrm{OO}$ genotypes) had a tendency to have more episodes of infection $(2.42, \mathrm{SD}=1.84)$ than those with $M B L 2$ wild-type genotype (AA genotypes) $(1.74, \mathrm{SD}=$ 1.04), $p=0.05$. However, no association between $M L B 2$ polymorphisms and the risk of Gram-positive (RR 1.02, 95\% CI 0.60-1.74), Gram-negative infections (RR 0.89, 95\% CI 0.52-1.52), viruses (RR 0.63, 95\% CI 0.30-1.34) or fungal infections (RR $0.31,95 \%$ CI $0.03-2.66$ ) was found during the first 6 months after the transplant. Supplementary Table 3 shows patients with MBL2 genotypes and risk of infections.

\section{Serum MBL levels and infection}

Patients with MBL levels $<1000 \mathrm{ng} / \mathrm{ml}$ in the pretransplant period presented the first post-transplant infection episode earlier (median $6 \mathrm{~d}$ vs. $8 \mathrm{~d}, p=0.036$, HR adjusted by conditioning regimen 1.72, 95\% CI 0.91-3.25) (Fig. 1). Additionally, a significant association was found between MBL levels $<1000 \mathrm{ng} / \mathrm{mL}$ in the pretransplant (before conditioning) and the risk of virus infection after Allo-HSCT, in the early (RR 2.48, 95\% CI 1.00-6.13), neutropenic (RR 3.28, 95\% CI 1.53-7.06) and intermediate periods (RR 2.37, 95\% CI 1.15-4.90). However, this finding was not observed in the late period. Among the virus infections, cytomegalovirus (CMV) was the most frequent infection (Table 2), and patients with low serum MBL levels had more episodes of CMV disease than those with normal levels, although these differences were not statistically significant. In the same way, no significant differences were observed between MBL levels and bacterial or fungal infections. The adjusted ORs are shown in Fig. 2 (2a, 2b, 2c, 2d).

\section{Effect of MBL levels and infections on survival}

Sixteen (22.2\%) patients died (7 with myeloablative conditioning and 9 non-myeloablative). Causes of death in 12 patients with MBL levels $<1000 \mathrm{ng} / \mathrm{mL}$, were: 6 patients died due to an infection (2 pulmonary aspergillosis, 2 Pseudomonas aeruginosa bacteremia, 1 Klebsiella pneumoniae bacteremia and 1 Pneumocystis jiroveci pneumonia), 2 patients because of graft versus host disease (GVHD), 2 patients due to a progression of the disease and 1 patient died due to a hemorrhage. Of the 4 patients who died and had MBL levels $>1000 \mathrm{ng} / \mathrm{mL}, 3$ died due to an infection (1 pulmonary aspergillosis, 1 Pseudomonas aeruginosa bacteremia and another one $E$. coli and Nocardia spp. bacteremia) and 1 due to a multiorgan failure of unknown cause. Aspergillus and viral infections were associated with mortality (Figs. 3 and 4). It was estimated that patients who developed Aspergillus infection had a 3.56-fold higher death hazard than patients who did not (95\% CI 0.99-12.70, $p=0.05$ ). Mean survival time over the 6-month follow-up period in patients with and without Aspergillus infection was 139.60 days (95\% CI $109.95-169.25$ ) and 161.16 days (95\% CI 150.40-171.92 respectively, $p=0.036$ ) (Fig. 3a). Similarly, patients with a virus infection had a 2.73-fold higher death hazard than patients who did not (95\% CI 0.99 $7.55, p=0.052$ ). Mean survival time over the 6-month follow-up period in patients with and without virus infection was 146.43 days (95\% CI 124.90-167.96) and 165.87 days (95\% CI $155.03-176.72$ respectively, $p=0.043$ ) (Fig. 3b).

$M B L 2$ genotypes were available in 12 out of the 16 patients who died (3 YA/YA, 3 XA/YA, 4 YA/O, 1 XA/ $\mathrm{O}$ and $1 \mathrm{O} / \mathrm{O})$. There was no relationship between the 


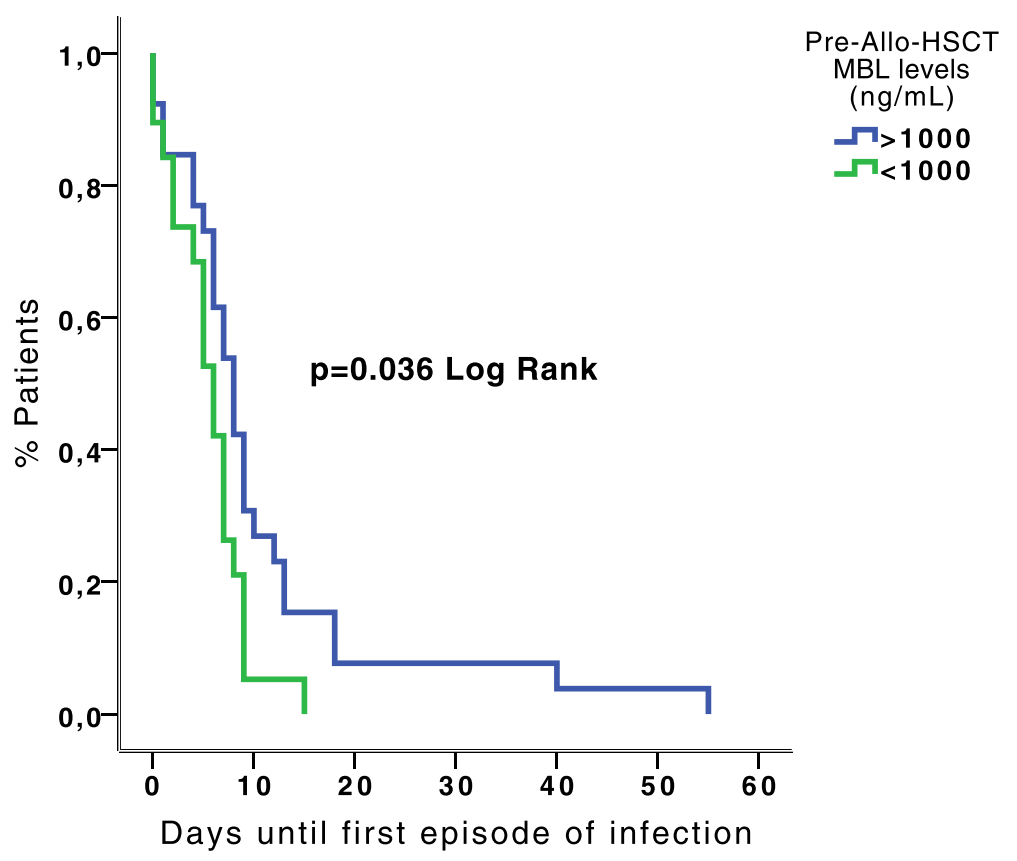

Fig. 1 Timing of the first post-transplant episode of infection in patients according to pre-Allo-HSCT MBL levels

MBL levels Pre-Allo-HSCT

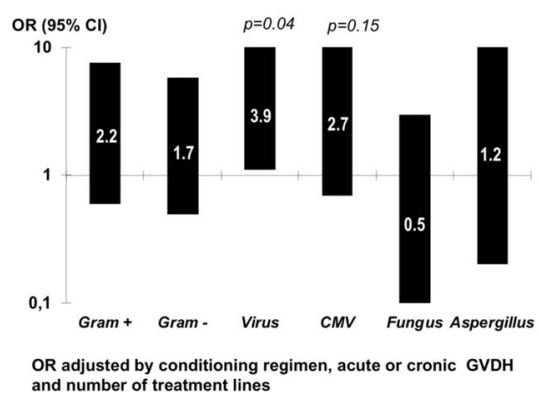

2d. Late period (100-180 d)

OR $(95 \% \mathrm{Cl})$

100

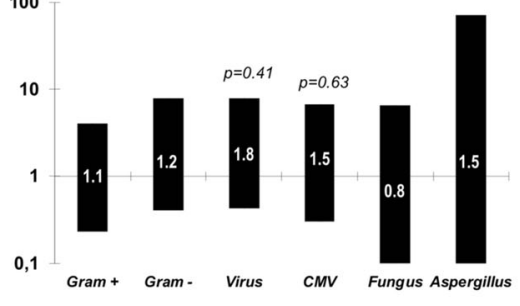

OR adjusted by conditioning regimen, acute or cronic GVDH and number of treatment lines 2b. Neutropenic period (0-30 d)

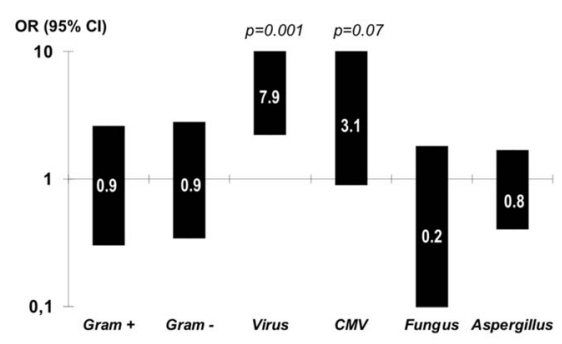

OR adjusted by conditioning regimen, acute GVDH and number of treatment lines

2d. Late period (100-180 d)

OR $(95 \% \mathrm{Cl})$

100

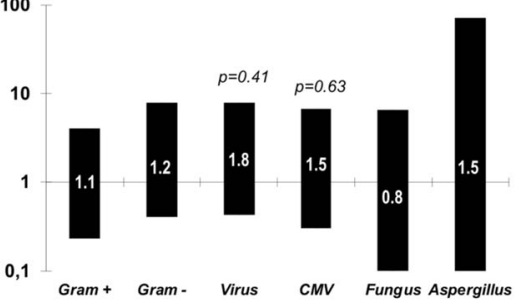

OR adjusted by conditioning regimen, acute or cronic GVDH and number of treatment lines

Fig. $2 \mathrm{MBL}$ levels $<1000 \mathrm{ng} / \mathrm{mL}$ and adjusted risk of bacterial, virus and fungal infections in 72 patients with Allo-HSCT. Figure 2a, MBL levels pretransplant (before conditioning); Fig. 2b, neutropenic period (0-30 d); Fig. 2c, intermediate period (30-100d) and Fig. 2d, late period (100-180 d) 


\section{a. Aspergillus infection}

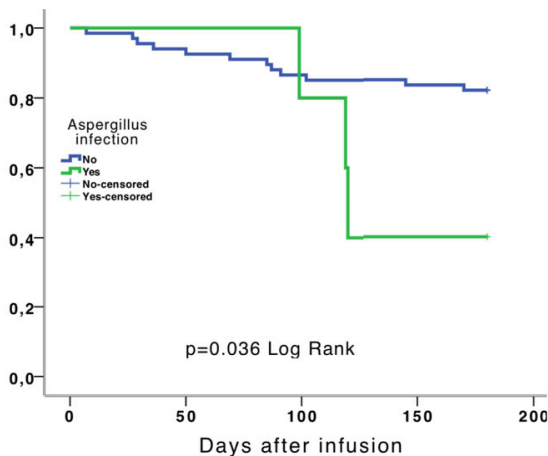

b. Virus infection

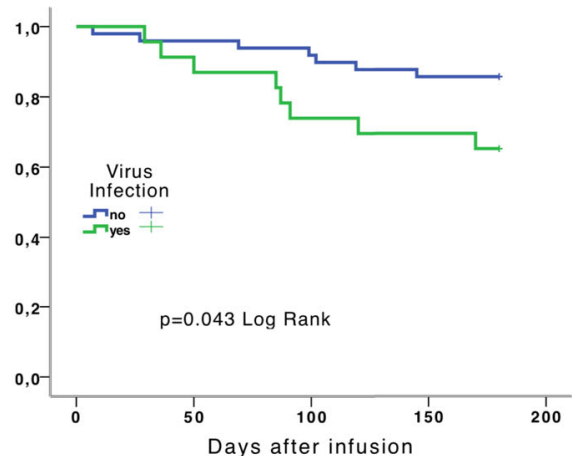

Fig. 3 Survival time according to presence of Aspergillus and viral infections over the 6 months follow-up. Figure 3a, Aspergillus infection; $3 \mathbf{b}$, virus infections

recipient's low producer $M B L 2$ genotypes and mortality (RR 1.26, 95\% CI 0.46-3.47, $p=0.44$ ). However, recipients with pre-transplant MBL levels $<1000 \mathrm{ng} / \mathrm{mL}$ had a significantly higher mortality rate than those with levels $>1000 \mathrm{ng} / \mathrm{mL}$ (HR 5.55, 95\% CI 1.17-26.30, $p=0.03$ ). In addition, the mean survival time of patients with pretransplant MBL levels < $1000 \mathrm{ng} / \mathrm{mL}$ was significantly lower (143.95 days; 95\% CI 121.49-166.41) than those with levels $>1000 \mathrm{ng} / \mathrm{mL}$ ( 169.15 days; 95\% CI $154.57-$ 183.66, $p=0.015)$. A Kaplan-Meier plot of survival by MBL status is shown in Fig. 4.

\section{Discussion}

This prospective study focused on analysing the influence of $M B L 2$ polymorphisms and MBL serum levels in the incidence of infections and outcome of myeloablative and non-myeloablative Allo-HSCT patients. Patients were followed from the conditioning until 180 days after transplant. To date, the studies describing the incidence of infections in Allo-HSCT related to $M B L 2$ gene variants and MBL levels have shown conflicting results.

The results of our study indicate that donor and/or recipient $M B L 2$ genotype was not associated with an increased number of infections by Gram-positive, Gramnegative, virus or fungal infections in the six months following transplantation. These findings contrast with those of Mullighan et al. [22] and Granell et al. [20], which showed that the MBL2 genotype of both recipients and donors influenced the risk of bacterial and invasive fungal infections, respectively, after Allo-HSCT.

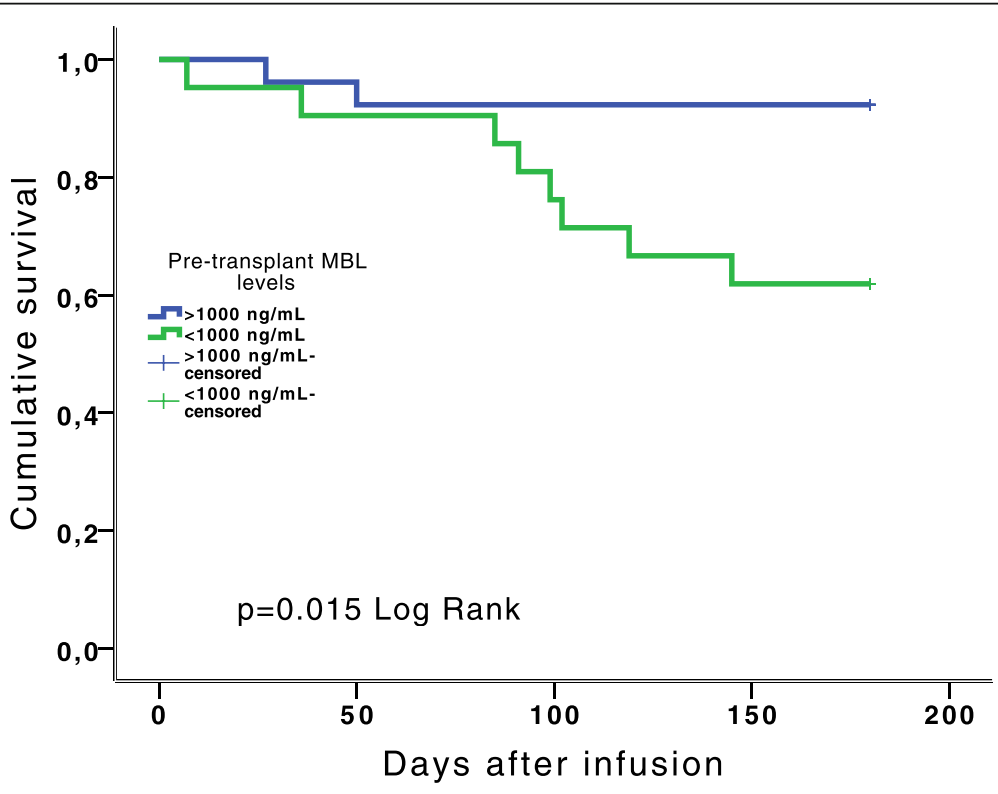

Fig. 4 Survival time by pre-Allo-HSCT MBL status over the 6 months follow-up 
However, our results did support those found by Neth et al. [23], which suggested that donors' $M B L 2$ genotype did not influence infection rates, and the results of Rocha et al. [21], who examined 107 HLA identical sibling Allo-HSCT recipients with myeloablative conditioning and found no association between $M B L 2$ gene polymorphisms and the development of bacterial, viral or fungal infections during the first 180 days after transplant. Currently, there are conflicting data about whether MBL deficiency is a good predictor of increased risk of infection. In our study, patients with pretransplant MBL levels $<1000 \mathrm{ng} / \mathrm{mL}$ presented the first episode of infection earlier on. Similar results have been published about neutropenic post-chemotherapy patients, in whom low MBL levels have also been described to be associated with earlier infections [9, 25]. In addition, patients with MBL levels $<1000 \mathrm{ng} / \mathrm{mL}$ in the pre-transplant and during the first 100 days after the transplant, had a significantly increased risk (2 to 8 times higher) of viral infection, mainly for CMV infection, although in this case the difference did not reach statistical significance. Our results are consistent with previously reported data regarding the association of viral infection and MBL deficiency [26-28]. MBL binds to influenza A virus, and therefore, it would inhibit haemagglutinin activity and infectivity [29]. Furthermore, MBL deficiency has also been related with herpes simplex virus (HSV)-2 infection and with CMV infection and reactivation in kidney and lung transplant recipients [28-30]. Nevertheless, different results have reported the association of MBL deficiency with viral infections in Allo-HSCT recipients [18, 19, 23]. Chaudhry et al. [19] did not find an association between MBL levels $<400$ $\mathrm{ng} / \mathrm{mL}$ and viral infections in 110 paediatric Allo-HSCT recipients. However, Neth et al. [23] found an association between MBL levels < $400 \mathrm{ng} / \mathrm{mL}$ and HSV/varicella zoster virus (VZV) reactivation in 131 Allo-HSCT recipients, and Osthoff et al. [18] showed an independent association between MBL levels $<1000 \mathrm{ng} / \mathrm{mL}$ and the occurrence of severe herpes virus infections in 44 Allo-HSCT recipients. These findings would suggest an important role of the innate immunity in the control of an important viral complication after Allo-HSCT transplantation.

Likewise, there are conflicting results or contradictory data about whether MBL2 genotypes or MBL deficiency could be used as mortality predictors in HSCT patients $[13,16,17,30,31]$. In the present study, the cause of death in all patients was infection, predominantly viral and Aspergillus infection. Recent report shows association of fungal invasive disease with death in patients with haematologic malignancy [13]. We did not find a relation between the recipient or donor $M B L 2$ genotype and mortality. Our findings are in agreement with those of Mulligan et al. [17], who did not find a relationship between mortality and MBL2 genotype, and disagree with our previous results in autologous HSCT [16] or those reported by other groups with immunosuppressed patients who had low-producing $M B L 2$ genotypes [30, 31]. On the other hand, we found that MBL levels < $1000 \mathrm{ng} / \mathrm{mL}$ could be a biomarker predictor of death since mortality was associated with low pre-transplant MBL levels. Similar findings have been published in patients with solid organ transplant, pneumonia or pneumococcal sepsis [32-34]. Low recipient serum MBL levels were associated with increased inflammation and apoptosis, [32] and have been described as an independent risk factor for poor prognosis in patients with pneumonia [35] and were associated with an increased severity of pneumococcal sepsis [34]. A meta-analysis published by Goa et al. in patients with sepsis showed a correlation between decreased MBL levels and development of sepsis, which the authors attributed to a possible interaction between coagulation patterns, proinflammatory cytokines and the complement system [35]. To date, there is a shortage of reports regarding the effects of MBL levels on the clinical outcome of AlloHSCT patients. A recent retrospective study by Riwes et al. [13] reported no association between low MBL levels and an increased risk of invasive fungal disease or overall survival in patients with haematologic malignancy.

This study presents some limitations. First that it is a single-centre study, with potential for uncontrolled selection biases and with small simple size. Nevertheless, is a prospective study without variation in the methodologies, something that does not occur when drawing patients from multiple centres. To avoid information bias, this was collected prospectively; the sample analysis was blinded for the presence or absence of infection and the measurement of the effect (presence of infection); the infectious disease physicians using the same diagnostic criteria (according to the IDSA criteria) carried out the analysis; and physicians responsible for the monitoring and diagnosis of infections were masked with respect to the presence of genetic polymorphisms and/or MBL levels. Second, this study finished time ago and the viral o fungal prophylaxis of infection could have been changed and could influence our results. However, the procedure of HSCT is totally similar to the performed in a Hematology Service at present and to our knowledge, there are no extensive studies in the last years regarding the role of MBL in Allo-HSCT; in addition, our study has an important value because of a prospective cohort that included patients with myeloablative and nonmyeloablative conditioning (the majority of studies on MBL and polymorphisms in patients with Allo-HSCT studied only those patients with myeloablative conditioning), this allows us to study a more heterogeneous 
population that is closer to the reality of the patients admitted to the Hematology Service. On the other hand, previous retrospective published studies on the role of innate immunity to infection or mortality in HSCT patients included old cohorts [14, 23], when probably viral and aspergillus prophylaxis were different to ours, with similar findings.

\section{Conclusions}

In summary, our results would suggest that low pretransplant MBL levels, but not MBL2 genotype, could predispose patients undergoing Allo-HSCT to have the first episode of infection earlier and to increase the risk of viral infection. This would support the hypothesis that phenotype might be more important than genotype in predicting susceptibility to viral infections since this association would be related with MBL levels. Moreover, low pre-transplant MBL levels and no MBL2 genotype would predict mortality in Allo-HSCT patients. Considering our findings, we could think that determination of the pre-Allo-HSCT MBL serostatus should be considered a useful biomarker for viral infection and mortality and should be included in the pre-transplantation risk assessment. However, given the contradictory findings that exist regarding the MBL studies after Allo-HSCT a larger study is required to replicate or refute our findings.

\section{Methods}

A prospective cohort study of all patients who received an Allo-HSCT was carried out between February 2007 and June 2009 at a tertiary care university hospital (1000-bed). All Allo-HSCT patients were $>13$ years old, and none of them presented any primary or secondary immunodeficiencies (solid neoplasms, HIV infection, autoimmune diseases). Patients were followed for a period of six months, after inclusion in the study.

\section{Endpoint definition}

Intercurrent infections were prospectively collected from the first day after infusion (day+1) and for the next 180 days after transplantation. We considered 3 periods: the early period ( $0-30$ days after Allo-HSCT), the intermediate period (30-100 days after Allo-HSCT) and the late period ( $>100$ days after Allo-HSCT). Infections were recorded by the clinical research associates from the institution using a standardized data collection form, following the protocols of the Hematology Department for autologous stem cell transplantation (ASCT) and AlloSCT [17], in agreement with the clinical guidelines of the Infectious Diseases Society of America (IDSA) [36]. Prophylactic measures included isolation in high-pressure rooms with air filters, the administration of intravenous acyclovir at prophylactic doses from day 3 , anti-bacterial prophylaxis with cotrimoxazole from day 30 after transplant and antifungal prophylaxis with fluconazole or caspofungin.

As previously described [17], we followed the protocols of the Hematology Department for definitions of an infectious episode (microbiologically or a clinically documented infection), major infection (either confirmed sepsis or systemic inflammatory response syndrome with highly suggestive radiographic or clinical features who received specific antibiotherapy); severe herpes virus infection (as an invasive viral infection requiring treatment and hospitalization); clinically significant CMV infection/reactivation (positive CMV blood culture or CMV-pp65 antigenemia assay or polymerase chain reaction (PCR) for CMV DNA ( 400 copies/mL, COBAS Amplicor CMV Monitor, Roche Diagnostics) and symptoms of organ dysfunction were required to fulfil the criteria of a clinically significant CMV infection/reactivation [37]). Episodes of asymptomatic CMV reactivation, local HSV reactivation, primary VZV, dermatological varicella zoster reactivation, patients with a single positive blood culture with contaminant skin bacteria, upper respiratory tract infections and culture-negative interstitial pneumonitis were excluded.

\section{MBL2 genotyping}

Blood samples from transplant patients was collected the day before the start of conditioning. In the case of donors, it was collected on the day of infusion in related donors. Eighteen unrelated donors were excluded for this analysis. There were 16 related donors in whom the sample could not be obtained; therefore, the determination of the genotype in the donors was finally performed in 34 patients. As previously described [17], genomic DNA from patients and controls was purified from blood samples by using the Maxwell 16 Genomic DNA Purification system (Promega Biotech Ibérica S.L., Madrid, Spain) and for $M B L 2$ gene amplification and genotyping, the INNO-LiPA MBL2 (Innogenetics Diagnostica Iberia S.L.U, Barcelona, Spain) was used, following the manufacturer's instructions. We analysed the 6 variations in the human $M B L 2$ gene $(-550 \mathrm{G}>\mathrm{C}$, $-221 \mathrm{G}>\mathrm{C},+4 \mathrm{C}>\mathrm{T}, \mathrm{R} 52 \mathrm{C}, \mathrm{G} 54 \mathrm{D}$, and G57E), the seven common haplotypes and the 28 possible resulting diplotypes. Exonic structural variants (A: normal allele, and B, $\mathrm{C}$ and $\mathrm{D}$ : mutant alleles, which together were designated allele $\mathrm{O})$ and promoter polymorphisms $(\mathrm{H} / \mathrm{L}, \mathrm{Y} / \mathrm{X}$ and $\mathrm{P} / \mathrm{Q}$ ) were analysed. Variants YA/YA, XA/XA and YA/XA were classified as $\mathrm{A} / \mathrm{A}$. Those with any mutation in the exon such as $\mathrm{YA} / \mathrm{O}$ and $\mathrm{XA} / \mathrm{O}$ were classified as $\mathrm{A} / \mathrm{O}$, and homozygous individuals with structural variants in the exon were considered $\mathrm{O} / \mathrm{O}$. Thus, patients were divided into two groups according to their $M B L 2$ genotype: 1 ) normal homozygous patients (AA), and 2) patients with 
$\mathrm{AO}$ and $\mathrm{OO}$ genotypes, who as described earlier, were considered to be lower MBL producers [15].

\section{MBL serum levels measurement}

Serum samples were used for the determination of MBL levels. These samples were obtained from patients before conditioning, weekly during the first month after the transplant and monthly during the following 5 months after the transplant. If an episode of infection occurred, biweekly serum was collected until the resolution of the episode.

Serum samples were collected and stored at $-80^{\circ} \mathrm{C}$ until analysis. Quantification of functional MBL was performed by an investigator blinded to any recipient data using a commercially available ELISA Kit (MBL Oligomer ELISA Kit, Bio Porto Diagnostics A/S, Copenhagen, Denmark) following manufacturer recommendations. Functional MBL deficiency was defined as serum levels below $1000 \mathrm{ng} / \mathrm{mL}[18]$.

\section{Statistical analysis}

As previously described [17], statistical analysis was performed, as required, using $\chi^{2}$ and Fisher's exact test when necessary, as well as Student's t test, or the Mann-Whitney test. A two-tailed $p<0.05$ was considered statistically significant. To analyse the association between MBL2 genotype and MBL levels, relative risks (RR) and adjusted odds ratios (OR) and their 95\% confidence intervals (CI) were calculated; the risk of concomitant infections was the dependent variable (overall and by microorganisms). The effect of MBL levels pre-transplant (before the start of conditioning) and after transplantation (early, intermediate and late periods) on the risk of infection, was analysed. Multivariate analysis was performed using logistic regression: a regression model was constructed for each type of infection, with infection-related variable being the outcome and the independent variable being the MBL2 genotypes and MBL levels, adjusted for sex, age, conditioning regimen, acute or chronic GVHD, and number of treatment lines. We used Kaplan-Meyer survival analysis with the log-rank test for comparisons between survival time and time to event or time until a certain event (1st infection). To estimate survival rate over time a Cox regression was applied as a function of several covariates. Hazard ratios (HR) and their $95 \%$ CI were calculated. Data were analysed using Stata (SE 10.0, Stata Corporation, College Station, TX) and SPSS (v19) (SPSS Inc., Chicago, IL) statistical software.

\section{Supplementary information}

Supplementary information accompanies this paper at https://doi.org/10. 1186/s12865-019-0318-8

Additional file 1: Table S1. Sociodemographic and medical conditions of each patient with Allo-HSCT. Table S2. Genotypes of MBL according to mutations of the exon and promoter, exon and $X / Y$ of the promoter and according to exon mutations in patients and donors. Table S3. Patients' MBL2 genotypes and risk of infections.

\section{Abbreviations}

Allo-HSCT: Hematopoietic allogeneic stem cell transplantation; Cl: Confidence Interval; CMV: Cytomegalovirus; DNA: Deoxyribonucleic Acid; GVHD: Graft Versus Host Diseases; HCV: Hepatitis C Virus; HIV: Human Immunodeficiency Virus; HLA: Human leukocyte antigen; HR: Hazard Ratio; HSV: Herpes simplex virus; IDSA: Infectious Diseases Society of America; MBL: Mannose-Binding Lectin; PCR: Polymerase Chain Reaction; RR: Risk Ratio; SCT: Stem cell transplantation; VZV: Varicella zoster virus

\section{Acknowledgements}

Part of this study was presented as an oral presentation at the 51st Interscience Conference on Antimicrobial Agents and Chemotherapy (ICAAC) (Chicago, September 2011; Session: 158- K-1118). The authors are indebted to J.D. García-Palomoł (Infectious Diseases Unit, Hospital Universitario Marques de Valdecilla, Santander, Spain) for his contribution to the study design and data analysis.

\section{Authors' contributions}

MP, PSV and FGOV carried out the experiments, and analyzed, and interpreted the data. CFA, AM, FGOV and MCF interpreted the data and discussed the results. CFA, JGOV and MCF contributed to the conception and design of the study, the analysis and interpretation of the data, and drafting and revising the manuscript. All authors read and approved the final manuscript.

\section{Authors' information}

*SCT team: A Batlle, Service of Hematology, Hospital Universitario Marqués de Valdecilla, Santander, Spain; E Conde, Service of Hematology, Hospital Universitario Marqués de Valdecilla, Santander, Spain; JP Horcajada, Infectious Diseases Unit, Hospital Universitario Marqués de Valdecilla, Santander, Spain, Current address: Hospital del Mar, Barcelona, Spain; C Montes, Service of Hematology, Hospital Universitario Marqués de Valdecilla, Santander, Spain; C Ruiz de Alegría, Service of Microbiology, Hospital Universitario Marqués de Valdecilla, Santander, Spain; M F Santos, División of Biochemistry, Hospital Universitario Marqués de Valdecilla, Santander, Spain.

\section{Funding}

This work was supported by grants from the Fondo de Investigaciones Sanitarias (Ministry of Health of Spain) PI04/0492 to MC Fariñas and Instituto de Investigación Sanitaria Valdecilla (IDIVAL) API 06/01. The content of the paper is solely the responsibility of the authors and does not necessarily represent the official views. The funding body was not involved in the design of the study, collection or analysis of the data, interpretation of the data, or in the writing of the manuscript.

Availability of data and materials

All data used and analyzed during the present study will be available from the corresponding author on reasonable request.

Ethics approval and consent to participate

This study was approved by the Ethics Committee of the Autonomous Community of Cantabria, Spain. All patients ( $>18$ years) signed informed consent forms to participate in the study. For children under 18 years, the parents were requested to sign the informed consent.

Consent for publication

Not applicable.

\section{Competing interests}

The authors declare that they have no competing interests.

\section{Author details}

'Service of Hematology, Hospital Universitario Marqués de Valdecilla, Santander, Spain. ${ }^{2}$ Present address: Service of Hematology, Hospital de Cruces, Bilbao, Spain. ${ }^{3}$ Division of Health Care Quality, Hospital Universitario Marqués de Valdecilla, Santander, Spain. ${ }^{4}$ Infectious Diseases Unit, Hospital 
Universitario Marqués de Valdecilla, IDIVAL, University of Cantabria, Av. Valdecilla s/n, 39008 Santander, Spain.

Received: 30 December 2018 Accepted: 20 September 2019 Published online: 09 November 2019

\section{References}

1. Kim SH, Kee SY, Lee DG, Choi SM, Park SH, Kwon JC, et al. Infectious complications following allogeneic stem cell transplantation: reducedintensity vs myeloablative conditioning regimens. Transpl Infect Dis. 2013; 15:49-59.

2. Frère $P$, Baron $F$, Bonnet $C$, Hafraoui $K$, Pereira $M$, Willems $E$, et al. Infections after allogeneic hematopoietic stem cell transplantation with a nonmyeloablative conditioning regimen. Bone Marrow Transplant. 2006;37:411-8.

3. Frère $P$, Hermanne JP, Debouge $M H$, de Mol P, Fillet $G$, Beguin $Y$. Bacteremia after hematopoietic stem cell transplantation: incidence and predictive value of surveillance cultures. Bone Marrow Transplant. 2004; 33:745-9.

4. Ip WK, Takahashi K, Ezekowitz RA, Stuart LM. Mannose-binding lectin and innate immunity. Immunol Rev. 2009;230:9-21.

5. Eisen DP, Minchinton RM. Impact of mannose-binding lectin on susceptibility to infectious diseases. Clin Infect Dis. 2003;37:1496-505.

6. Thiel S, Kolev M, Degn S, Steffensen R, Hansen AG, Ruseva M, et al. Polymorphisms in mannan-binding lectin (MBL)-associated serine protease 2 affect stability, binding to MBL, and enzymatic activity. J Immunol. 2009; 182:2939-47.

7. Thiel S, Frederiksen PD, Jensenius JC. Clinical manifestations of mannanbinding lectin deficiency. Mol Immunol. 2006:43:86-96.

8. Schlapbach LJ, Aebi C, Otth M, Luethy AR, Leibundgut K, Hirt A, et al. Serum levels of mannose-binding lectin and the risk of fever in neutropenia pediatric cancer patients. Pediatr Blood Cancer. 2007;49:11-6.

9. Vekemans M, Robinson J, Georgala A, Heymans C, Muanza F, Paesmans M, et al. Low mannose-binding lectin concentration is associated with severe infection in patients with hematological cancer who are undergoing chemotherapy. Clin Infect Dis. 2007:44:1593-601.

10. Bergmann OJ, Christiansen M, Laursen I, Bang P, Hansen NE, Ellegaard J, et al. Low levels of mannose-binding lectin do not affect occurrence of severe infections or duration of fever in acute myeloid leukaemia during remission induction therapy. Eur J Haematol. 2003;70:91-7.

11. Frakking FN, Israëls J, Kremer LC, Kuijpers TW, Caron HN, Van de Wetering MD. Mannose-binding lectin (MBL) and the risk for febrile neutropenia and infection in pediatric oncology patients with chemotherapy. Pediatr Blood Cancer. 2011:57:89-96.

12. Lausen B, Schmiegelow K, Andreassen B, Madsen HO, Garred P. Infections during induction therapy of childhood acute lymphoblastic leukemia - no association to mannose-binding lectin deficiency. Eur J Haematol. 2006;76:481-7.

13. Riwes MM, Leather $H$, Neal D, Bennett C, Sugrue M, Cline C, et al. Association of mannose-binding lectin levels and invasive fungal disease in hematologic malignancy patients receiving myelosuppressive chemotherapy or allogeneic hematopoietic stem cell transplantation. Bone Marrow Transplant. 2016;51:1228-32.

14. Eleutherakis-Papaiakovou E, Dimopoulos MA, Kastritis E, Christoulas D, Roussou M, Migkou M, Gavriatopoulou M, Fotiou D, Panagiotidis I, Ziogas DC, Kanellias N, Papadimitriou C, Terpos E. Low circulating mannan-binding lectin levels correlate with increased frequency and severity of febrile episodes in myeloma patients who undergo ASCT and do not receive antibiotic prophylaxis. Bone Marrow Transplant. 2017;52(11):1537-42.

15. Mølle I, Peterslund NA, Thiel S, Steffensen R. MBL2 polymorphism and risk of severe infections in multiple myeloma patients receiving high-dose melphalan and autologous stem cell transplantation. Bone Marrow Transplant. 2006;38:555-60.

16. Horiuchi T, Gondo H, Miyagawa H, Otsuka J, Inaba S, Nagafuji K, et al. Association of MBL gene polymorphisms with major bacterial infection in patients treated with high-dose chemotherapy and autologous PBSCT. Genes Immun. 2005;6:162-6.

17. Moreto A, Fariñas-Alvarez C, Puente M, Ocejo-Vinyals JG, Sánchez-Velasco P, Horcajada JP, et al. Mannose-binding lectin gene variants and infections in patients receiving autologous stem cell transplantation. BMC Immunol. 2014;15:17.
18. Mullighan CG, Heatley SL, Danner S, Dean MM, Doherty K, Hahn U, et al. Mannose-bindins lectin status is associated with risk of major infection following myeloablative sibling allogeneic hematopoietic stem cell transplantation. Blood. 2008;112:2120-8.

19. Osthoff M, Rovó A, Stern M, Danner D, Gratwohl A, Tichelli A, et al. Mannosebinding lectin levels and major infections in a cohort of very long-term survivors after allogenic stem cell transplantation. Haematologica. 2010;95:1389-96.

20. Chaudhry SH, Chaudhry S, Jansen-Hoogendijk AM, Jol van der Zijde CM, van Tol MJ, Roos A, et al. Mannose-binding lectin levels and infections in children after allogeneic hematopoietic SCT. Bone Marrow Transplant. 2010;45:289-93.

21. Granell M, Urbano-Ispizua A, Suarez B, Rovira M, Fernández-Avilés F, Martínez C, et al. Mannan-binding lectin pathway deficiencies and invasive fungal infections following allogeneic stem cell transplantation. Exp Hematol. 2006;34:1435-341.

22. Rocha V, Franco RF, Porcher R, Bittencourt H, Silva WA Jr, Latouche A, et al. Host defense and inflammatory gene polymorphisms are associated with outcomes after HLA-identical sibling bone marrow transplantation. Blood. 2002;100:3908-18.

23. Mullighan CG, Heatley S, Doherty K, Szabo F, Grigg A, Hughes TP, et al. Mannosebinding lectin gene polymorphisms are associated with major infection following allogeneic hemopoietic stem cell transplantation. Blood. 2002;99:3524-9.

24. Neth OW, Bacher U, Das P, Zabelina T, Kabisch H, Kroeger N, et al. Influence of mannose-binding lectin genotypes and serostatus in Allo-SCT: analysis of 131 recipients and donors. Bone Marrow Transplant. 2010;45:13-9.

25. Kilpatrick DC, Stewart K, Allan EK, McLintock LA, Holyoake TL, Turner ML. Successful haemopoietic stem cell transplantation does not correct mannan-binding lectin deficiency. Bone Marrow Transplant. 2005;35:179-81.

26. Kase T, Suzuki Y, Kawai T, Sakamoto T, Ohtani K, Eda S, et al. Human mannan-binding lectin inhibits the infection of influenza a virus without complement. Immunology. 1999;97:385-92.

27. Gadjeva M, Paludan SR, Thiel S, Slavov V, Ruseva M, Eriksson K, et al. Mannan-binding lectin modulates the response to HSV-2 infection. Clin Exp Immunol. 2004;138:304-11.

28. Manuel O, Pascual M, Trendelenburg M, Meylan PR. Association between mannose-binding lectin deficiency and cytomegalovirus infection after kidney transplantation. Transplantation. 2007;83:359-62.

29. Kwakkel-van Erp JM, Paantjens AW, van Kessel DA, Grutters JC, van den Bosch JM, van de Graaf EA, et al. Mannose-binding lectin deficiency linked to cytomegalovirus (CMV) reactivation and survival in lung transplantation. Clin Exp Immunol. 2011;165:410-6.

30. Hellemann D, Larsson A, Madsen HO, Bonde J, Jarløv JO, Wiis J, et al. Heterozygosity of mannose-binding lectin (MBL2) genotypes predicts advantage (heterosis) in relation to fatal outcome in intensive care patients. Hum Mol Genet. 2007;16:3071-80.

31. Cervera C, Balderramo D, Suárez B, Prieto J, Fuster F, Linares L, et al. Donor mannose-binding lectin gene polymorphisms $b$ influence the outcome of liver transplantation. Liver Transpl. 2009;15:1217-24.

32. Ibernon M, Moreso F, OValle F, Grinyo JM, Moral RG, Seron D. Low serum mannose-binding lectin levels are associated with inflammation and apoptosis in early surveillance allograft biopsies. Transplant Immunol. 2014:31:152-6.

33. Liu XH, Li Q, Zhang P, Su Y, Zhang XR, Sun Q. Serum mannose-binding lectin and $\mathrm{C}$-reactive protein are potential biomarkers for patients with communityacquired pneumonia. Genet Test Mol Biomarkers. 2014;18:630-5.

34. Eisen DP, Dean MM, Boermeester MA, Fidler KJ, Gordon AC, Kronborg G, et al. Low serum mannose-binding lectin level increases the risk of death due to pneumococcal infection. Clin Infect Dis. 2008;47:510-6.

35. Gao D-N, Zhang Y, Ren Y-B, Kang J, Jiang L, Feng Z, et al. Relationship of serum mannose-binding lectin levels with the development of sepsis: a meta-analysis. Inflammation. 2015;38:338-47.

36. Hughes WT, Armstrong D, Bodey GP, Bow EJ, Brown AE, Calandra T, et al. 2002 guidelines for the use of antimicrobial agents in neutropenic patients with cancer. Clin Infect Dis. 2002;34:730-51.

37. Razonable RR, Paya CV, Smith TF. Role of the laboratory in diagnosis and management of cytomegalovirus infection in hematopoietic stem cell and solid-organ transplant recipients. J Clin Microbiol. 2002;40:746-52.

\section{Publisher's Note}

Springer Nature remains neutral with regard to jurisdictional claims in published maps and institutional affiliations. 